\title{
DEVELOPING MARKETING STRATEGIES FOR FOOD DIVERSITY : A CASE-STUDY IN NORTHERN PORTUGAL
}

\begin{abstract}
Isabel DINIS, Instituto Politécnico de Coimbra, Escola Superior Agrária de Coimbra, Bencanta, 3045-601 Coimbra, Portugal, idinis@esac.pt (corresponding author)

Pedro MENDES-MOREIRA, Instituto Politécnico de Coimbra, Escola Superior Agrária de Coimbra, Bencanta, 3045-601 Coimbra, Portugal,pmm@esac.pt

Susanne PADEL, Organic Research Centre, Elm Farm, Hamstead Marshall, Newbury RG20 0HR, United Kingdom, susanne.p@organicresearchcentre.com

Vale do Sousa is a heterogeneous territory located in the North Region of Portugal. Until a few decades ago, the economy was based on small-scale farming with maize for bread (Broa) as one important crop. Each community had its own maize varieties and practices, which were reflected in the composition, shape, size and flavour of local Broa. In the last decades, the abandonment of agriculture was noticeable, leading to a progressive decrease in maize production and to genetic erosion. More recently, local stakeholders became aware of the important role that landraces and biodiverse food can play in local development and have engaged in finding new opportunities for a sustainable Broa value chain development in Vale do Sousa region. This paper aims at identifying opportunities and bottlenecks in the marketing of regional Broa. It uses a case study approach that, unlike the majority of the research in this area, covers the whole supply chain and includes needs and expectations of farmers, processors, consumers and their networks. The main problem identified by local actors is that traditional varieties are less productive, leading farmers to favour commercial maize varieties less suitable for baking. At the processing level, local actors raised the question of legislation, arguing that, in Portugal, European rules on food safety are not realistically applied to endogenous food products. The results also show that final consumers as well as restaurants recognize the quality of traditional Broa and seem to be willing to pay a price premium to reward farmers for using traditional varieties.
\end{abstract}

Keywords: bread; landraces; local development; maize; participatory research

\section{INTRODUCTION}

Vale do Sousa is a heterogeneous territory located in the North Region of Portugal, at a small distance from the Portuguese second largest city - Oporto. It includes the municipalities of Castelo de Paiva, Felgueiras, Lousada, Paços de Ferreira, Paredes and Penafiel. The population density and the percentage of young people are very high when compared to the country and to the North Region. The manufacturing industry currently employs around half the active population but, until a few decades ago, the economy was founded on small farming agriculture with maize for bread as one important crop.

Maize was introduced in Portugal shortly after Christopher Columbus's pioneering voyage in 1492. The crop fast expanded in the center and north coast regions of the country and completely transformed rural livelihoods, having a strong impact at technological (irrigation, fertilizing, livestock production) landscape and social levels. Maize was used to feed the animals and to produce maize bread (Broa) that, at the time, almost completely replaced the traditional wheat or rye bread. Maize bread has become a fundamental element of the food system and regional culture. Furthermore, together with wine, maize became the currency in which rents were paid and farmers wealth was measured (Caldas, 1991).

The north and central coast regions, remain nowadays the most important Portuguese areas of maize farming and traditional Broa production, following a recipe of millet bread (Borona) referred in Portuguese documents dating from the 12th century (Rocha et al., 2003). Due to the lack of gluten in the maize, Broa is usually prepared with rye, in order to make the bread leavened and lighter. Traditionally, Broa was made at home by women, generally once a week. Each community had its own maize varieties and practices, which were reflected in the composition, shape, size and flavour of local Broa.

In the last decades, the abandonment of agriculture in general and maize for food in particular was noticeable. In fact, between 1989 and 2015, in northern Portugal the area of maize was reduced to one third and production was reduced by half (INE, 1992 and 2016). In the 1980s and 1990s farmers in Vale do Sousa largely replaced maize for human consumption by maize for animal feed. However, more recently, small farmers have abandoned livestock farming and were left with small plots, with areas under 0.5 ha, for which it is difficult to find a profitable substitute crop. Following the same trend, a progressive decrease in the production and use of traditional varieties also occurred, leading to a decrease

Copyright (C) 2017 The Authors. Published by Aleksandras Stulginskis University. This is an open-access article distributed under the terms of the Creative Commons Attribution License (CC-BY 4.0), which permits unrestricted use, distribution, and reproduction in any medium, provided the original author and source are credited. 
in Broa quality caused by the use of varieties unsuited for baking. At the same time, the traditional knowledge related to the selection of varieties and the production of maize bread was neglected.

The scientific community awareness of genetic resources coevolution started in the 1980's, when it was understood the need for in situ/on farm conservation. Under this frame, a maize participatory plant breeding (PPB) program was developed at Vale do Sousa (VASO Project) based on the representativeness of the region in national maize production, farmers' motivation and germplasm availability (Mendes Moreira et. al, 2017). One of the indirect results of the project was the opportunity to interact with local initiatives, such as 'Vale do Sousa Best Ear Annual Contest' (selection for big ears) organized by the local Farmers' Cooperative Association (Cooperativa Agrícola de Paredes). The connection between local actors and initiatives, enhanced by VASO project, provided an excellent basis to expand the concern about traditional varieties conservation and local food products promotion. Nowadays some traces of the traditional practices remain but only in household production, for family consumption and direct selling.

Within this context, several local actors engaged on an application process for the registration of the Protected Designation of Origin (PDO) "Broa do Vale do Sousa". The application dossier was delivered to the national authority in 2008 but was never sent to the European Commission on the grounds that the production area should be extended. Currently, local stakeholders remain interested in developing a marketing plan that gives visibility to Broa, considering that it can be an important lever for local development. In addition to the dietary value, traditional Broa is a public good, resulting from empirical evolution over many generations, having the status of cultural heritage. It is not possible to speak about Vale do Sousa gastronomy and traditions without mentioning Broa (Rocha et al., 2003).

The main objective of the present research is to produce guidelines and recommendations, in order to enhance food diversity by finding new opportunities for sustainable Broa value chain development in Vale do Sousa region. In order to better achieve this goal, it is necessary to learn from past failed marketing and valorisation strategies, to identify conditioning organisational, socio-economic, institutional and political factors, and to understand stakeholders aims and strategies. Specific research questions are: "What are the main bottlenecks and barriers for the development of a marketing strategy?", "Who benefits from the added value of Broa (producers, retailers, consumers)?" and "How can policy/networks and the legal and institutional framework support Broa Value chain development and valorisation strategies?"

The research is part of the European Project DIVERSIFOOD ${ }^{1}$ and follows the same conceptual framework, applying traditional marketing theory to agricultural and rural business. As stated by Goi (2009), one of the founders of the academic discipline of marketing (McCarthy, 1964) extended the issue of the single P (price) of microeconomic theory to the "marketing mix" framework, often referred to as the 4Ps (Product, Price, Place, and Promotion). Details on the debate around the Mix as marketing paradigm and predominant marketing management tool are widely illustrated in the literature, including Möller (2006) and Goi (2009). The main criticism is that the concept of 4Ps is a production-oriented definition of marketing, and not a customer-oriented (Popovic, 2006). By converting product into customer solution, Lauterborn (1990) further developed the 4P's approach in to the 4Cs (Consumer value and benefits, Cost, Convenience, Communication), making clear that marketing is not just an activity aimed at the promotion of any product, but a strategy that affects the whole supply chain. This idea is the theoretical starting point of the present study. However, empirical studies aiming at identify critical factors of successful / unsuccessful marketing strategies and to analyse in detail the whole process of value adding and communication from the seed breeder to the consumer are scarce. A few studies, such as Hamm (1991), Schmid et al. (2004) and Mehdi et al. (2014) are some of the few exceptions.

\section{RESEARCH METHODS}

This paper uses a case study approach, developed by researchers from the University of Pisa (UNIPI), the Organic Research Centre (ORC) and the Research Institute of Organic Agriculture (FiBL) (Rossi et al., 2016). The starting point of the authors framework is that successful market introduction and valorisation requires collaboration and communication between all the actors involved (breeders and multipliers, farmers, technicians, processors, retailers, intermediate users and final consumers, and, in some cases, other actors) as well as a range of enabling factors. Therefore, the present case study covers the whole supply chain and includes needs and expectations of farmers, processors, consumers, local policy makers and their networks. As a research method, case study methodology is well established in Social Sciences, especially in qualitative research, making it possible to compile a nuanced, holistic, and detailed analysis of a selected place, group, or process (Hardwick, 2009, Yin, 2014). The value of the case study approach is well recognised in several fields such as medicine, policy, business and marketing and rural development (e.g. Bond et al., 2001, Agyepong and Adjei, 2008, Forsman, 2008, Stauffacher et al., 2008, Crowe et al., 2011, Brindley and Oxborrow, 2014). The method has been widely used for the study of alternative food networks, for example in the context of marketing of organic food (Midmore et al., 2004).

Data collection was performed between July 2016 and February 2017 involving two focus-groups with consumers and 14 semi-structured interviews with local stakeholders. The first focus-group took place in Vale do Sousa with 10 local consumers and the other one in Coimbra, the biggest city in the Center region of the country, with 12 participants. The participants in the first focus-group and interviews were first suggested by experts from the Local Action Group (LAG) Ader-Sousa. After being selected by the research team, they were personally contacted by Ader-Sousa to be informed

\footnotetext{
${ }^{1}$ The Diversifood project has received funding from the European Union's H2020 programme under Grant Agreement
} 633571 . 
about the research project and the objectives of the survey and to be asked about their willingness to participate. When they agreed to it, a date for the interview was scheduled. Both groups were carried out face-to-face by the same experienced interviewer. The participants in the Coimbra focus-group were selected among the consumers of an important local bakery after being suggested by the bakery owner.

Regarding the interviews, the idea was to listen to the opinions of different actors along the supply chain. Since, in Vale do Sousa, is not easy to separate handmade Broa producers, producing for household consumption and short supply chains, from food maize farmers, it was decided to interview 6 farmers/bakers. A mid-size miller and two local gastronomy specialized restaurants owners were also interviewed. Although the restaurants were their main business, both of them also had rural tourism facilities. Two cooperative leaders (Cooperativa Agrícola de Lousada and Cooperativa Agrícola de Paredes) were also interviewed as well as two experts from the two LAG - Ader-Sousa and Dolmen. Finally, a representative of local public actors also participated in the survey.

Both the interviews and focus groups were recorded, followed by transcription and content analysis. All the results presented in the next section of the paper refer only to the points of view conveyed by the interviewees and participants in the focus group. The authors' perspectives on any of the topics investigated are completely absent.

\section{RESULTS}

\section{Actors perception of the specific attributes of traditional Broa}

The traditional Broa from Vale do Sousa is a home baked bread, made by a typical method which requires the exclusive use of maize flour, rye (or wheat) flour, sourdough starter, water and salt. The maize flour used preferably comes from local ecotypes and old varieties. The bread's characteristics, highlighted by consumers and other participants in the case study, are its greyish color, its crunchy brown crust, its low porosity and its highly distinctive taste and aroma to maize. Broa is sweet, unsalted and slightly acidic, keeping in perfect conditions for a week under ambient conditions. Along with other food products, Broa is one of the components of the Mediterranean diet. Such a diet has been considered as a vector for the prevention of cardiovascular diseases. Furthermore, maize bread is a gluten-free product, suitable for people with celiac disease.

Besides legal food safety standards, there are no rules regarding traditional Broa production in Vale do Sousa. Maize is sometimes milled in water mills and, in other cases, in electric mills. Each baker uses his own recipe: usually maize flour is mixed with rye flour but wheat flour is also used. In any case, proportions are variable. Besides, the bread may be baked in wooden or electric ovens. Although the use of maize flour of traditional varieties is recognized by most participants as a quality constraint, a significant proportion of traditional Broa is currently produced with flour from hybrid maize. Frequently, the bread is kneaded by women in their home kitchens, not always respecting the standards imposed by the national food safety authority.

One issue that was raised by participants was the impact of the grain drying process on flour and Broa quality. Conventionally, maize ears are stored in traditional drying structures, called espigueiros, and later thrashed and milled. However, some participants argued that this technique contributes to an unpleasant taste of flour and Broa. In order to obtain good flour, ears must be trashed and grains dried before storage. The milling process also seems to be important for quality. The miller in our study has the opinion that there is a difference between watermill and electric mill flour, even if both use a millstone. Watermills have slower rotations and flour becomes thinner and softer.

\section{Advantages and disadvantages of using traditional maize varieties}

The participants in the case study identified specific qualitaty attributes of traditional varieties in relation to bread. It is argued that traditional Broa have a better storage capacity. While common Broa using modern varieties is good only on the same day that is baked, traditional Broa keeps in good quality for a week. The flavour of the bread is also referred by most participants. According to them, traditional Broa has an obvious maize flavour and is sweeter than common Broa. At the same time, as some participants argued, regional varieties have the advantage of being well adapted to local environmental conditions, reducing farmers' dependence on external inputs. Besides, the ability of the seeds to be stored and used year on year, may have some impact on reducing costs of production.

However, traditional varieties also present some shortcomings when compared to modern varieties. At the farm level it is stressed out by farmers that traditional varieties are less productive. The reported differences vary from 35 to $70 \%$ less yield when compared to modern hybrids. This is the main reason pointed out by farmers to drop traditional varieties and to replace them with more productive ones less suitable for bread-making. Lower yield derives not only from the plant's genetic potential but also from crop management. For instance, traditional varieties need more space, hence lower plant density. They are thought to be more susceptible to stalk and root lodging due to wind or heavy rains. Less resistance to diseases, when compared to hybrids and genetically modified lines, is another disadvantage of traditional varieties often mentioned by farmers. At the processing level, it has been reported that the grains of traditional varieties are always harder, leading to lower mill durability. Furthermore, while common grain is delivered to the mill, traditional varieties must be collected at the farms, increasing the miller cost.

The main obstacles that consumers face when buying traditional Broa are related to convenience, since traditional Broa is not available in usual supermarkets or in most local bakeries and restaurants. It may be easy for local consumers to find traditional Broa because they are familiar with the local supply chain, the lack of labels and identification in the stores makes it difficult for visitors to buy the genuine product. Furthermore, many traditional bakers produce Broa only 
a few days a week and sell door-to-door to regular customers on scheduled days. These days may not be suitable for some consumers and the system hinders the access to new customers that are not familiar with the procedures.

\section{Conservation and management of traditional maize varieties}

Contrary to what happens in many other countries, Portugal has an important legacy of traditional maize varieties specifically for human consumption. Some are still preserved on farm, others in national gene banks, but usually without a strategy for long-term use. According to participants, there are currently no farmers producing exclusively maize using traditional varieties in Vale do Sousa. The few that still grow them, do it in small plots with the main purpose of producing homemade bread for family consumption and to preserve the varieties inherited from their parents. In the past, different types of varieties were used, in different intercropping combinations that were adapted to particular soil and climatic conditions and met specific agronomic and production goals. The most common combination was maize with beans or maize with beans and pumpkins, but other crop mixtures were also used. Participants in the interviews and focus-groups were able to identify 4 traditional varieties: Verdial de Cete, Verdial de Aperrela, Pigarro and Fandango. Some farmers still refer to HP21 and HB3 as traditional varieties but, in fact they originated as hybrids that were kept by farmers for decades and managed as landraces, suitable for bread. Verdial is currently the most cultivated traditional variety, being grown mainly together with beans or potatoes.

Besides farmers, both local associations (LAG and cooperatives) and local public actors perceive the preservation of genetic heritage as one of their priorities. Nevertheless, their present involvement mainly relies on the organization of events designed to promote local products. For some time, The Municipality of Lousada also sponsored the farmers involved in the VASO project. As for the Cooperatives, they have left for some time to deliver seeds of traditional varieties to their members. Even Cooperativa Agrícola de Paredes, that was deeply involved in "Vale do Sousa Annual Best Ear Contest" is no longer involved in any genetic resource management activity.

The general perception is that the aging of farmers and the abandonment of agriculture will lead to the disappearance of these varieties unless something is done to prevent it. Participants largely agree that the main bottleneck lies at the farm level and suggest that a new assessment of farmers, varieties and production levels should be made. Only by encouraging farmers to produce traditional varieties it will be possible to avoid the loss of that important genetic and cultural heritage. Broa certification (Protected Designation of Origin (PDO), Protected Geographical Indication (PGI) or other) was pointed as crucial so that farmers can receive a fair price for their maize. It was also suggested that an incentive payment per hectare of traditional varieties could be given to farmers. At the same time, research institutions should strengthen the work with regional maize in order to obtain more productive and resistant plants. Farmers will try different varieties only if they have guaranties that they are productive and fairly paid. Several participants raised the question of seed availability and the need for seed collection at the farmer field level. One of the cooperatives leaders expressed his commitment to promote seed certification and marketing. In this respect it was also stressed that seed certification processes take years and that current legislation on conservation varieties is very restrictive of traditional varieties seed marketing.

Finally, it was emphasized that only with the awareness of all actors in the value chain, particularly farmers and Broa consumers, would it be possible to preserve the traditional maize varieties of Vale do Sousa, as well as traditional Broa. It was stressed the need to promote actions to raise local consciousness so that the entire local population perceives the value of such heritage.

\section{Interaction between actors in Broa supply chain}

In general, at present, there is little interaction between actors from different levels of the Broa supply chain and also between actors at the same level of the chain. Each actor tends to relate to others only when tangible needs arise, such as the purchase of raw materials or services. Relationships are sporadic, volatile, with no formal framing. This has not always been the case. In order to develop the application for the Protected Designation of Origin (PDO) "Broa do Vale do Sousa", Ader-Sousa established a number of contacts with farmers and bakers, cooperatives, mills and local associations that cooperate in the process. Strong relationships were also established between local actors and several research institutions, some of whom have resisted to this day.

It is recognized by all stakeholders that the revitalization of a local Broa supply chain should involve all those that can add some value to the process. The opinion of the LAG experts is that these processes can only achieve success when partnerships between local and national institutions, cooperatives, economic agents and city councils are enhanced. Regarding leadership, participants' opinions are divided mainly between Ader-Sousa and farmer cooperatives. Some participants also referred the city councils as potential leaders of the initiative.

Although a traditional Broa specific network does not exist, it is worth mentioning that all municipalities have a Social Development Plan (SDP) in which a project like Traditional Broa could be inserted. The SDP is a local policy instrument in which the municipality's strategic framework for intervention and social development is conceived and developed. It defines objectives and strategies capable of responding to the needs and problems previously identified in the social diagnosis. This plan is drawn up by several local partners and links them as a common change project. In a region, all the municipal plans are then articulated in a supramunicipal plan, allowing the establishment of combined strategies in order to respond to the common and priority problems of the territory. It is important to mention that the main actors (or their representatives) involved in the traditional Broa supply chain are members of a Supramunicipal Social Network. In this context, awareness activities and the construction of collective storage, processing and distribution structures could be actions to be included in a broad Traditional Broa project. These ideas were conveyed by the agricultural cooperatives leaders and, more insistently, by the representative of the local city councils (public actors). 


\section{Marketing and communication of the product}

Regarding the product, consumers in the focus-groups mentioned the main associations that come to their minds when they think about traditional Broa. These are tradition, culture, ancient knowledge, ancestral origin, natural product, maize flavour as well as good chorizo and good wine. A consumer commented that traditional varieties give her a certain confidence of being genuine, real, with no mixing and no change of flavours. Several participants in the Coimbra focus group also made reference to the product being free from genetically modified organisms (GMO) or organic.

Several remarks revealed that Broa is very present in participants' mind as a pleasant memory: "this bread reminds me of my childhood; we would sow the corn, dry it, send it to grind, and then my mother would bake the Broa at home; I still have these flavours very present in my mind"; "when I was a child I lived in OPorto and the memory I have from coming to my grandmother house is the chicken soup and the Broa, especially because my grandmother would make some delicious Broa crumbs with milk"; "I still remember my grandmother baking bread in a communal oven; two or three women joined together, each putting her bread in the oven and baking it together; each one had its distinguishing sign; then, they placed the Broas on trays, all leaning against one another, wrapped in a linen cloth; I thought that was wonderful; "my grandmother made a small Broa filled with what each of us (we were five brothers and sisters) liked the most (sardines, ham, chorizo)".

Most actors in Vale do Sousa agree that a Broa labelled as traditional should be produced with regional/ancient/traditional maize varieties, but there is not a strict consensus. Some farmer/bakers think that the important feature is the Broa artisanal method of production rather than the flour origin. Besides, they argue, the mandatory use of traditional varieties will greatly limit Broa supply, at least in the short term. One of them even expressed the view that "no label is required because the product speaks for itself".

Regarding the method of production, opinions also diverge. A more open view is that the recipe should be free as well as the percentage of varieties allowed in the flour blend. To overcome potential consumer misperception, a reference to the producer could be put in the package. It is argued that this is the way local Broa market currently works. People choose one baker or another, depending on the Broa features they are looking for in each particular circumstance. Others, however, highlight the problems that production diversity may cause to the establishment of a new PDO or PGI.

Regarding price, farmer/bakers state that they should receive $2.00 € / \mathrm{Kg}$ to be rewarded for producing Broa from traditional varieties, while the price of traditional Broa is around $1.20 € / \mathrm{Kg}$. The price is around $15 \%$ higher, but the production may be less than half then commercial varieties. That's why they choose commercial maize varieties with a processing performance similar to traditional varieties rather than the traditional varieties themselves.

Concerning consumers, most participants in the Coimbra focus-group expressed curiosity and willingness to pay more for Broa of traditional varieties than for the conventional bread they usually eat. The consumers in Vale do Sousa focus-group were more aware of Broa production constraints. They argued that regional maize cannot compete with hybrids and GMO's because the yield is less than half and, therefore, the price cannot be the same. If the price is not higher production is not sustainable. In their opinion, a product such as Broa from Vale do Sousa can and should be more expensive. They stated that they are willing to pay more for quality and tradition. If the difference in price is considerable but also in organoleptic properties, they would opt for the best Broa, as long as the price was not disproportionate. It is worthwhile noticing that owners of traditional food restaurants are not worried about the price, since bread does not represent a significant cost. Their main concern about Broa is the quality.

Regarding place, it is possible to find Broa in most bakeries in Vale do Sousa region, food shops and restaurants although traditional Broa is somehow rare. Usually, Broa is made at the end of the week and sold on the farm, directly to consumers or restaurants or to middlemen, who will then sell door-to-door to particular customers. Some baker/farmers also sell to local shops. At the weekend it is also possible to buy this kind of bread at Cooperativa Agricola de Lousada. Less often, traditional Broa is produced in small bakeries, whose owners purchase maize from local farmers that they know or from millers who grind traditional varieties or maize with characteristics close to these varieties. Most of the Broa is delivered locally.

Most of the participants in the case-study have the opinion that traditional Broa is a specialty food and, therefore, a marketing plan is needed and selling places should be careful selected. The most referred desired channels, in order to avoid trivialization were: properly identified local restaurants and bakeries and gourmet food shops in large urban centers. They also expressed the opinion that cooperatives should play a role in the supply chain. At present a project is being developed by all the municipalities of the Portuguese North Region with the objective of promoting and selling the typical products of the Region using a business model that includes 55 shops. This project could play a major role in the development of the traditional Broa initiative, enabling a fairer distribution of value along the supply chain.

Participants pointed out that the price of traditional Broa also depends on the marketing strategy. It can be twice the price of industrial Broa, perhaps not in the day-to-day sale, but connected to catering, accompanying certain traditional dishes, and associated with local events (wine tastings, sausages and cheeses fairs). A successful marking strategy would require good consumer information and promotion. Nowadays, people are very concerned about health. Therefore, information should be given on raw material, method of production and health features such as "low in gluten".

Regarding promotion, there is some controversy on the type of label to implement as well as in its designation. The majority of respondents express a preference for PDO, probably because a PDO application has already been submitted. As pointed out by a GAL expert, in a PDO, besides the characterization of the production process, regional varieties have to be specified while for the PGI label it is enough to certify the production process. In the current context, since the seeds of the regional varieties of maize are not yet certified, it would be easier to create a PGI. However, that 
option would mean losing years of studies and work already made in Vale do Sousa and give up on-farm conservation of traditional varieties.

Since the previous application of the PDO "Broa do Vale do Sousa" was not successful mainly because of the production area limits, it was asked to participants what should be the territorial boundaries and designation if a new label was to be created. The most common answer was that it should still "Vale do Sousa". However, when faced with the region's low supply capacity, several participants admitted the possibility of extending the production area to contiguous regions. They argued that the most important of all is to certify the traditional Broa using an attractive label linked to the territory and that the type of designation itself is a detail.

\section{Partnership for a sustainable Broa value chain development}

The creation of a label was found relevant by all interviewees, with the exception of two, and all of them declared to be interested to participate in such a process. Broa is a distinct quality product and a way of promoting the territory. It is closely linked to local traditions and gastronomy. Most local restaurants present Broa to their customers, even if it is sometimes industrial. For local actors, a label for traditional Broa could support local development, similarly to what currently happens with wines and other certified products. Not only because the increases in production and the value in the whole Broa chain, but also because it may improve income in other sectors, namely gastronomy and tourism. The growing interest of some new farmers in endogenous products, as well as the increase in demand, are seen by local actors as opportunities for an initiative aiming at the establishment of a label for local traditional Broa.

The main threats to the success of such an initiative, as pointed out by several participants in this study, are the declining number of farmers and the extinction of maize traditional varieties. At the processing level bottlenecks also exist. In the traditional process some practices must be adjusted to comply with the national legal context. For example, people still bake at their home kitchens, typically using wooden utensils. Furthermore, the diversity in methods of production can also be a problem. While it is true that this diversity is in the Broa tradition, it may hamper the implementation of a label. The opinions of local actors on this issue are not unanimous. While some consider that diversity is intrinsic to the product and should be maintained, others believe that some standardization of the method of production should be pursued. The same happens with the production territory. Some have de opinion that Broa produced outside Vale do Sousa is not the same, because agro-ecological conditions and gastronomy and traditions differ, but others have a broader view stating that those differences are details that can be overcome.

Two major challenges were identified by participants: the mobilisation of farmers and bakers' for the production and use of traditional maize varieties and the label recognition by the market. In this respect, local development associations and farmer cooperatives may have an important role in communicating with the local actors, on the basis of the mutual knowledge and trust that has been built over years of joint collective action. It is however recognized that building a strong partnership involving farmers, bakers, restaurants and other stakeholders takes time.

It is also argued by most participants that legislation negatively affects traditional food products. The rules applied to traditional production facilities are the same as those applied to industrial production. There is no adaptation or flexibility in the interpretation of European directives, contrary to what happens in most other European countries. Participants referred to the feeling that the European Union assigns lots of funds to the endogenous products but this is not reflected in real policies. As participants highlight, in most Portuguese PDO regions artisans were unable to meet the costs of legalizing their small production units. Those who had the capacity to invest, industrialized their units and the others gave up production. Currently in most PDO regions only industrial or semi-industrial production remains. In general, participants think that the traditional method of production must be respected, since it identifies the product and justifies a protected name or qualification. If the method of production is changed, specificity and distinction of other similar products will be lost. It is not acceptable to be too rigid when it is acknowledged that standards not always fit reality.

\section{CONCLUSIONS}

In the last decades, the abandonment of the production and use of maize for food, particularly using traditional varieties, lead to a decrease in Broa quality. Being aware of the economic, social and cultural importance of Broa in Vale do Sousa, several local actors are becoming more interested in developing a marketing strategy that gives visibility to Broa and also to traditional maize varieties. It is recognized that the use of such varieties is related to specific Broa quality, mainly at the organoleptic and storage capacity levels. Maize for food is a crop that most farmers are familiar with and could be valued when used in regional traditional Broa production. The traditional varieties, namely Pigarro, have excellent characteristics to be used in bakery, allowing to develop the Broa value chain.

However traditional varieties are less productive and more susceptible to bad weather and diseases and therefore farmers have lost interest in growing them, unless their families bake Broa for their own consumption. This problem is identified by local actors as one of the most significant threats to the success of an initiative aiming at the implementation of a traditional Broa label.

The main incentive identified by farmers to encourage them to produce traditional varieties is a higher price. This case study shows that final consumers as well as restaurants are in fact willing to pay a price premium to reward farmers for the lower yield associated with traditional varieties. At the processing level, local actors raised the question of legislation as one of the major threats for the process, arguing that, in Portugal, European rules on food safety are not realistically applied 


\section{Proceedings of the $8^{\text {th }}$ International Scientific Conference Rural Development 2017}

to endogenous food products. Finally, the choice of a single method of production, the definition of the production territory and the choice of an actual label can also be seen as threats since the opinions of local actors are not unanimous.

While this case study provides interesting insights regarding local actors' views on local genetic resources and marketing of biodiverse products, it should be complemented by more specific studies designed to assess the minimum price-premium needed to compensate farmers for agrobiodiversity preservation efforts as well as to deeply understanding consumers' preferences and willingness to pay.

\section{Acknowledgments}

The research leading to these results has received funding from the European Union's Horizon 2020 research and innovation programme under grant agreement No 633571.

\section{REFERENCES}

1. Agyepong, I., Adjei, S. 2008. Public social policy development and implementation: a case study of the Ghana National Health Insurance scheme. Health Policy and Planning, Vol. 23 (2), pp. 150-160. https://doi.org/10.1093/heapol/czn002

2. Bond, R., Curran, J., Kirkpatrick, C., Lee, N., Francis, P. 2001. Integrated Impact Assessment for Sustainable Development: A Case Study Approach. World Development, Vol. 29, pp. 1011-1024. https://doi.org/10.1016/S0305-750X(01)00023-7

3. Brindley, C., Oxborrow, L. 2014. Aligning the sustainable supply chain to green marketing needs: A case study. Industrial Marketing Management, Vol. 43, pp. 45-55. https://doi.org/10.1016/j.indmarman.2013.08.003

4. Caldas, E. 1991. A Agricultura Portuguesa através dos Tempos (Portuguese agriculture through time), Instituto Nacional de Investigação Científica, Lisboa.

5. Crowe, S., Cresswell, K., Robertson, A., Huby, G., Avery, A., Sheikh, A. 2011. The case study approach. BMC Medical Research Methodology, Vo. 11:100 https://doi.org/10.1186/1471-2288-11-100

6. Forsman, H. 2008. Business development success in SMEs: a case study approach, Journal of Small Business and Enterprise Developmentm, Vol. 15 (3), pp. 606-622. https://doi.org/10.1108/14626000810892382

7. Goi, C. 2009. A Review of Marketing Mix: 4Ps or More? International Journal of Marketing Studies, Vol. 1(1), pp. $2-15$. https://doi.org/10.5539/ijms.v1n1p2

8. Hamm, U. 1991. Landwirtschaftliches Marketing: Grundlagen des Marketings for landwirtschaftliche Unternehmen, Verlag Eugen Ulmer, Stuttgart.

9. Hardwick, S. W. 2009. Case Study Approach. In International Encyclopedia of Human Geography, edited by K. Editors-in-Chief: Rob and T. Nigel, Elsevier, Oxford https://doi.org/10.1016/B978-008044910-4.00408-9

10. INE. 1992. Recenseamento Geral Agrícola 1989 (General Census of Agriculture 1989), Instituto Nacional de Estatística, Lisboa.

11. INE. 2016. Estatísticas Agrícolas 2015 (Agricultural Statistics 2015), Instituto Nacional de Estatística, Lisboa.

12. Lauterborn, B. 1990. New Marketing Litany: Four Ps Passé: C-Words Take Over. Advertising Age, Vol. 61(41), p. 26.

13. McCarthy, J. 1964. Basic Marketing: A Managerial Approach, IL Irwin, Homewood.

14. Mendes Moreira, P., Dinis, I., Santos, D., Patto, M. 2017. VASO Program 2.0, three decades of participatory plant breeding towards the chain value, Paper Presented at the Scientific Conference "Innovative Research for Organic Agriculture 3.0", 19 World Congress, New Delhi, India, November 9-11.

15. Midmore, P., Foster, C. Schermer, M. 2004. Organic Producer Initiatives and Rural Development - four European Case Studies. University of Wales, Aberystwyth. Available at https://shop.fibl.org/de/artikel/c/sonderangebote/p/1348-producer-initiatives.html.

16. Möller, K. 2006. The Marketing Mix Revisited: Towards the 21st Century Marketing by E. Constantinides. Journal of Marketing Management, Vol. 22(3), pp. 439-450. https://doi.org/10.1362/026725706776861181

17. Popovic, D. 2006. Modelling the Marketing of High-Tech Start-Ups. Journal of Targeting, Measurement and Analysis for Marketing, Vol. 14(3), pp. 260-276. https://doi.org/10.1057/palgrave.jt.5740186

18. Rocha, J., Brás, A., Trigueiros, J., Malcata, X. 2003. Pão de Milho: Caracterização do Produto Tradicional e Melhoramento Tecnológico (Corn Bread: Characterization of the Traditional Product and Technological Improvement), Universidade Católica Portuguesa, Escola Superior de Biotecnologia, Porto.

19. Rossi, A., Padel, S., Brunori, G., Gerrard, C., Oehen, B. 2016. Diversifood Case Study Framework (MS 27)

20. Schmid, O., Richter, T., Hamm, U., Dahlke, A. 2004. A Guide to Successful Organic Marketing Initiatives. OMIARD FIBL, Frick.

21. VALSOUSA. 2011. O Vale do Sousa (Sousa Valley). Available at http://www.valsousa.pt/valsousa/o-vale-do-sousa (Accessed on $6 / 1 / 2017)$.

22. Stauffacher, M., Flüeler, T., Krütli, P., Scholz, R. 2008. Analytic and dynamic approach to collaboration: a transdisciplinary case study on sustainable landscape development in a Swiss prealpine region. Systemic Practice and Action Research, Vol. 21(6), pp. 409-422. https://doi.org/10.1007/s11213-008-9107-7

23. Yin, R. 2014. Case Study Research Design and Methods, 5th ed., CA Sage, Thousand Oaks. 